\title{
Use of Facebow in Fabrication of Complete Denture among Saudi Prosthodontist
}

ISSN: 2637-7764

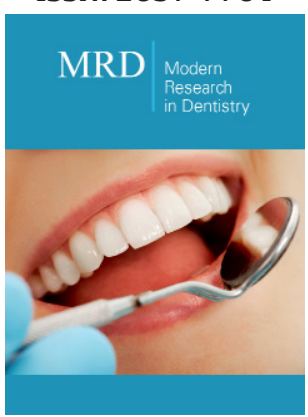

*Corresponding author: Mohammed $\mathrm{Al}$ Attas, Consultant in prosthodontic, Dental implant and Maxillofacial Prosthodontics, Riyadh Dental Hospital, King Saud Medical City, Riyadh, Saudi Arabia

Submission: 战 September 24, 2021

Published: 僵October 19, 2021

Volume 6 - Issue 5

How to cite this article: Mohammed $\mathrm{A}$ Attas, Safa Zarea Al Dali, Duaa Omar Qallely. Use of Facebow in Fabrication of Complete Denture among Saudi Prosthodontist. Mod Res Dent. 6(5). MRD. 000648. 2021. DOI: 10.31031/MRD.2021.06.000648

Copyright@ Mohammed Al Attas, This article is distributed under the terms of the Creative Commons Attribution 4.0 International License, which permits unrestricted use and redistribution provided that the original author and source are credited.
Mohammed Al Attas ${ }^{1 *}$, Safa Zarea Al Dali² and Duaa Omar Qallely ${ }^{3}$

${ }^{1}$ Consultant in prosthodontic, Dental implant and Maxillofacial Prosthodontics, Riyadh Dental Hospital, King Saud Medical City, Riyadh, Saudi Arabia

${ }^{2}$ Bachelor degree of Dentistry, Higher Diploma Implant Dentistry, Riyadh Elm University, Riyadh, Saudi Arabia

${ }^{3}$ Bachelor degree of Dentistry, Higher Diploma Implant Dentistry, Riyadh Elm University, Riyadh, Saudi Arabia

\begin{abstract}
Background: Objectives In a double-blind, randomized clinical trial, the effect of recording face-bow curvature for complete denture recombination (CDs) on occlusal coefficients was evaluated. The fine fitting of dental casts on the articulator is one of the main procedures that allow the accurate analysis, diagnosis and treatment planning for edentulous patient. Some researchers believe that the face-bow is indispensable, as it brings with it many advantages.
\end{abstract}

Aim: The aim of the study is to assess the use of facebow and attitude toward it among prosthodontists in complete denture fabrication.

Material and Methods: A questionnaire consisting of 13 questions has been prepared to assess and evaluate knowledge about Facebow in the manufacture of complete dentures, along with additional information about the educational background and experience of prosthodontists, the attitude towards the facebow in the manufacture of complete dentures, patient satisfaction, and the reason behind not using the facebow and their knowledge About the jaw connection and occlusal adjustment in the manufacture of complete dentures. This questionnaire was sent to 149 clinics in the Kingdom of Saudi Arabia for prosthodontists regardless of age, gender and experience. The questionnaire has been emailed to you. Clear instructions were provided in the questionnaire form regarding the purpose of this survey and answering the questions. The name, contact details, mail ID, location and educational qualifications of the participants are kept strictly confidential.

Result: More than $90 \%$ of study subjects responded positively that, it is easy to use face bow. Among those who had used it in complete denture fabrication, the frequency of use was 'every time' in $28.9 \%$, often in $33.6 \%$ and seldom in $32.2 \%$ of subjects. If the study subjects did not use the face bow, the specified reasons by them were, ' it is time-and energy consuming' (30.7\%), and 'I do not think it is necessary (55.3\%).

Conclusion: Within the limits of this study, it can be concluded that there is no significant difference in post-insertion visits for complete dentures made with and without the face record. The majority of prosthodontists believe that most of their patients were satisfied with their full dentures, rarely using a face-bow.

Keywords: Complete dentures; Facebow; Occlusal adjustment; Articulator; Prosthodontist

\section{Introduction}

Facebow a mechanical instrument that represents the temporomandibular joints and jaws, to which maxillary and mandibular casts may be attached to simulate some or all mandibular movements. Primary purposes of an articulator are Hold opposing casts in a predetermined fixed relationship, stimulate jaw movement like Open and close, produce border and intra- 
border diagnostic sliding motions of the teeth similar to those in the mouth, receive craniodental and maxillo-mandibular relations and three dimensions of the oral organ receive the axes of mandibular rotations, Guide to incorporate these factors into the prosthesis [1-4]. The occlusal morphology of any restoration for the mouth must accommodate the free passage of the opposing teeth without interfering with the movement of the mandible.

Facebow directs the dental cast in the same relationship with the joint opening axis; Usually the anatomical references are the transverse horizontal axis of the lower funnel and another specific anterior point. Correct fitting of dental splints on the joint is one of the delicate procedures that allow accurate analysis, diagnosis, and treatment planning for a patient without dental problems. A mechanical instrument that represents the temporomandibular joints and jaws, to which maxillary and mandibular casts may be attached to simulate some or all mandibular movements. Facebow was 1st introduced by George Snow in 1899, with the intention of locating the rotation axis of the lower jaw. Since then, the use of facebow has become a controversial topic [5-9].

Some research has thought that the face arch is indispensable and has many advantages, however, many research has considered facebow to be a useless method in addition to being time- or energyconsuming procedures. The quality of complete dentures was not reported to be affected when manufacturing techniques were simplified to save time. Well- done research shows that there is no significant difference in outcome between dentures manufactured by the two methods, with or without the use of facebow. The use of appropriate methods other than facebow used, such as making an impression that allows for a more accurate and applicable procedure or establishing a good relationship between the denture and the patient is more important to the success of the treatment $[10,11]$.

\section{Material and Methods}

The aim of the study is to assess the use of facebow and attitude toward it among prosthodontists in complete denture fabrication.

A total of 149 prosthodontists in different Saudi Dental Clinics were included in the study. A questionnaire consisting of 13 questions was sent to them prepared to assess and evaluate the knowledge on facebow in fabrication of complete dentures, along with additional information on the education and experience background of prosthodontists, the attitude toward facebow in complete denture fabrication, patient satisfaction, reason behind not using the facebow and their knowledge about jaw relationship and occlusal adjustment in complete denture fabrication, a questionnaire was sent to them covering the following aspects:

a. Education background.

b. Their impression of the quality of denture

c. The uses of attitudes toward a facebow in complete

\section{denture the fabrication}

d. The reason behind not using the facebow

e. Their knowledge about jaw relationship and occlusal adjustment in complete denture fabrication.

The survey was sent by Google Drive to all dental prosthesis specialists in the clinics of the Kingdom of Saudi Arabia. All 149 respondents completed the questionnaire completely.

1. Your education background?

2. The length of time you have worked as a prosthodontist?

3. The number of complete dentures you have finished?

4. Do you think it is easy to use?

5. Do you use a face- bow in complete denture fabrication?

6. If you do not use the face-bow, what is the reason?

7. What do you think about using and not using the face-bow in complete denture fabrication?

8. Do you think the quality of the denture made with a simple articulator differs from the adjustable articulator?

9. Do you think the patients you have treated have been satisfied with their dentures?

10. Do you think the quality of the newly made dentures is associated with denture materials?

11. Do you think the quality of the newly made dentures is associated with technique?

12. Do you think the quality of the newly made dentures is associated with mandibular position registration?

13. Among the following factors, which is the first one influencing the quality of the complete dentures?

\section{Statistical analysis}

Data were analyzed using SPSS 26.0 windows version statistical software (IBM Inc., Chicago USA). Descriptive statistics (frequencies and percentages) were used to describe the categorical variables. Pearson's Chi-square test was used to compare the distribution of categorical variables and to observe an association between the categorical variables. A p-value of $\leq 0.05$ was used to report the statistical significance of results.

\section{Result}

Out of 149 study subjects $36.2 \%$ of them had Master's degree, followed Ph.D. Bachelor and other degrees as their educational status. About $47 \%$ of them were having $<5$ years of experience as a prosthodontist and $60.4 \%$ of them were having experience in finishing $<50$ complete dentures and $17.4 \%$ of them were having in finishing $>150$ complete dentures (Table1). 
Table 1: Distribution and comparison of study subject's perceptions responses towards use of Facebow.

\begin{tabular}{|c|c|c|c|}
\hline Items of Perceptions & Responses, No.(\%) & $\mathrm{X}^{2}$-value & p-value \\
\hline \multicolumn{4}{|c|}{$\begin{array}{l}\text { What do you think about using and not using the face-bow in complete denture } \\
\text { fabrication? }\end{array}$} \\
\hline No difference & $50(33.6)$ & 30.14 & $<0.0001$ \\
\hline Not using it may lower the quality to some extent & $56(37.6)$ & & \\
\hline Not using it may lower the quality at large & $29(19.5)$ & & \\
\hline Not sure & $14(9.4)$ & & \\
\hline \multicolumn{4}{|c|}{$\begin{array}{l}\text { Do you think the quality of the denture made with a simple articulator differs from } \\
\text { the adjustable articulator? }\end{array}$} \\
\hline Yes, they are different & $102(68.5)$ & 164.69 & $<0.0001$ \\
\hline Yes, there is a small difference & $34(22.8)$ & & \\
\hline No different & $11(7.4)$ & & \\
\hline I don't know & $2(1.3)$ & & \\
\hline \multicolumn{4}{|c|}{ Do you think the patients you have treated have been satisfied with their dentures? } \\
\hline Yes, most of them (over 90\%) satisfied & $102(68.5)$ & 182.41 & $<0.0001$ \\
\hline About half of them satisfied & $44(29.5)$ & & \\
\hline No, most of them are not satisfied & $2(1.3)$ & & \\
\hline I don't know & $1(0.7)$ & & \\
\hline \multicolumn{4}{|c|}{$\begin{array}{l}\text { Do you think the quality of the newly made dentures is associated with denture } \\
\text { materials? }\end{array}$} \\
\hline Yes, closely associated & $64(43.0)$ & 74.27 & $<0.0001$ \\
\hline Yes, but only partially & $62(41.6)$ & & \\
\hline No, not associated & $19(12.8)$ & & \\
\hline I don't know & $4(2.7)$ & & \\
\hline \multicolumn{4}{|c|}{ Do you think the quality of the newly made dentures is associated with technique? } \\
\hline Yes, closely associated & $126(84.6)$ & 284.1 & $<0.0001$ \\
\hline Yes, but not closely & $15(10.1)$ & & \\
\hline No, not associated & $4(2.7)$ & & \\
\hline I do not know & $4(2.7)$ & & \\
\hline \multicolumn{4}{|c|}{$\begin{array}{l}\text { Do you think the quality of the newly made dentures is associated with mandibular } \\
\text { position registration? }\end{array}$} \\
\hline Yes, closely associated & $109(73.2$ & 187.78 & $<0.0001$ \\
\hline Yes, but not closely & ) 22(14.8) & & \\
\hline No, not associated & $12(8.1)$ & & \\
\hline I do not know & $6(4.0)$ & & \\
\hline \multicolumn{4}{|c|}{$\begin{array}{l}\text { Among the following factors, which is the first one influencing the quality of the } \\
\text { complete dentures? }\end{array}$} \\
\hline Jaw relationship & $56(37.6)$ & 59.62 & $<0.0001$ \\
\hline Central occlusion contact relationship & $17(11.4)$ & & \\
\hline Balanced occlusion & $65(43.6)$ & & \\
\hline No difference between the three factors & $11(7.4)$ & & \\
\hline
\end{tabular}

The distribution and comparison of perceptions towards use of Face bow shows highly statistical significance difference in all the 7 items responses. For the item ' what do you thing about using and not using the face-bow in complete denture fabrication, $33.6 \%$ of them responded as 'no difference' and $37.6 \%$ of them as 'not using it may lower the quality to some extent' which are statistically significantly higher when compared with the other two options responses of this item $(\mathrm{p}<0.0001)$.More than $60 \%$ of subjects had responded as 'yes they are different' to the perception item 'Do you think the quality of the denture made with a simple articulator 
differs from the adjustable articulator?' which is statistically significantly higher than the responses of other options $(\mathrm{p}<0.0001)$ [12-15]. More than two third of subjects (68.5\%) had stated that, 'yes, most of them (over 90\%) satisfied', to the perception item ' do you think the patients you have treated have been satisfied with their dentures?' which indicates statistically significantly higher proportion of response when compared to the other options $(p<0.0001)$. The proportion of responses were as 'yes, closely associated' by $43 \%$ and 'yes, but only partially' by $41.6 \%$ of study subjects for the perception item,' do you think the quality of the newly made dentures is associated with denture materials?' which is statistically significantly higher proportion of responses $(\mathrm{p}<0.0001)$. And similar response of ' yes, closely associated ' by $84.6 \%$ and by $73.2 \%$ of subjects to the two perception items ' do you think the quality of the newly trade dentures is associated with technique?' and 'Do you think the quality of the newly made dentures is associated with mandibular position registration', which shows significantly higher proportion of response to this option when compared with the proportion of other three options for these two perception items $(\mathrm{p}<0.0001)$. Among the 4 options, $43.6 \%$ of them had chooses an option of 'balanced occlusion' and $37.6 \%$ of them an option of 'jaw relationship ' as the factors which were influencing first in the quality of complete dentures' which is statistically significant ( $p<0.0001)$.The association between the responses of perception towards use of face bow and educational status of study subjects shows statistically significant association between the responses of item (what do you thing about using and not using face-bow in complete denture fabrication?) where higher proportion of responses ' no difference', ' not using it may lower the quality to some extent' and 'not using it may lower the quality at large' by subjects who had bachelor \& master degrees as their educational status. These proportions (50\%, 50\% and 62.1\%) were significantly higher when compared with the proportions of similar responses of subjects with qualifications of $\mathrm{PhD}$., and other degrees $(\mathrm{p}=0.001)[16-18]$.

Similar pattern of higher proportion of responses for the options of other 5 items of perceptions, were observed by the subjects of bachelor \& master's degree qualifications and the statistically significant association were not able to observe due to the distribution of small frequencies in the responses. No statistically significant association was found between the responses of perception item,' among the following factors, which is the first one influencing the quality of the complete dentures?' and study subject's educational status $(\mathrm{p}=0.371)$. The association between the responses of perception towards use of facebow and two levels of working experience as prosthodontist of study subjects shows statistically significant association between the responses of item ( do you think the quality of the denture made with a simple articulator differs from the adjustable articulator ?) where higher proportion (78.4\%)of responses ' yes they are different' by subjects who had $<=10$ years of experience as prosthodontist and $63.6 \%$ of responses as ' no different' by subjects who had $>10$ years of experience as prosthodontist, which indicates statistically significant association $(\mathrm{p}=0.001)$. Also statistically significant association was observed between the responses of two perception items ( do you think the quality of the newly made dentures is associated with mandibular position registration? and among the following factors which is the first one influencing the quality of the complete dentures?) where the proportion of responses to the 4 options under this items differs between the subject who had <= 10years and $>10$ years of experience as prosthodontist ( $\mathrm{p}=0.002$ $\& \mathrm{p}=0.024)$. No statistically significant association was observed between the responses other two perceptions items and study subjects experience levels as prosthodontist ( $p=0.435 \& \mathrm{p}=0.282$ ) [19-21].

About the association between the responses of perception towards use of face bow and three levels of number of complete dentures by study subjects shows statistically significant association for the responses of item( among the following factors, which is the first one influencing the quality of the complete dentures?), where among the 4 options, $76.5 \%$ responses as 'central occlusion contact relationship' $67.7 \%$ as 'balanced occlusion' and $37.6 \%$ as 'jaw relationship' by subjects who had completed $<50$ dentures indicates statistically significant association between the responses and level of number of completed dentures $(p=0.019)$. No statistically significant association was observed between the responses of the item (what do you think about using and not using the face-bow in complete denture fabrication?) and level of number of completed dentures $(\mathrm{p}=0.348)$.

More than $90 \%$ of study subjects responded positively that, it is easy to use the facebow (Figure 1). Among those who had used it in complete denture fabrication, the frequency of use was 'every time' in $28.9 \%$, often in $33.6 \%$ and seldom in $32.2 \%$ of subjects (Figure $2)$. If the study subjects did not use the facebow, the specified reasons by them were, 'it is time- and energy consuming' (30.7\%), and ' I do not think it is necessary (55.3\%) (Figure 3).

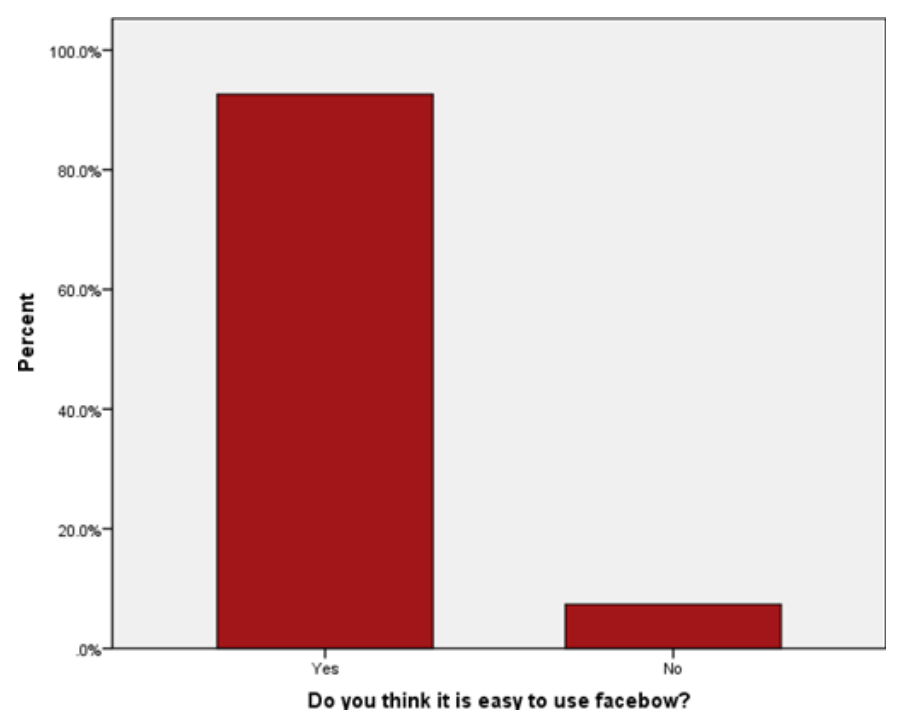

Figure 1: Do you think it is easy to use? 


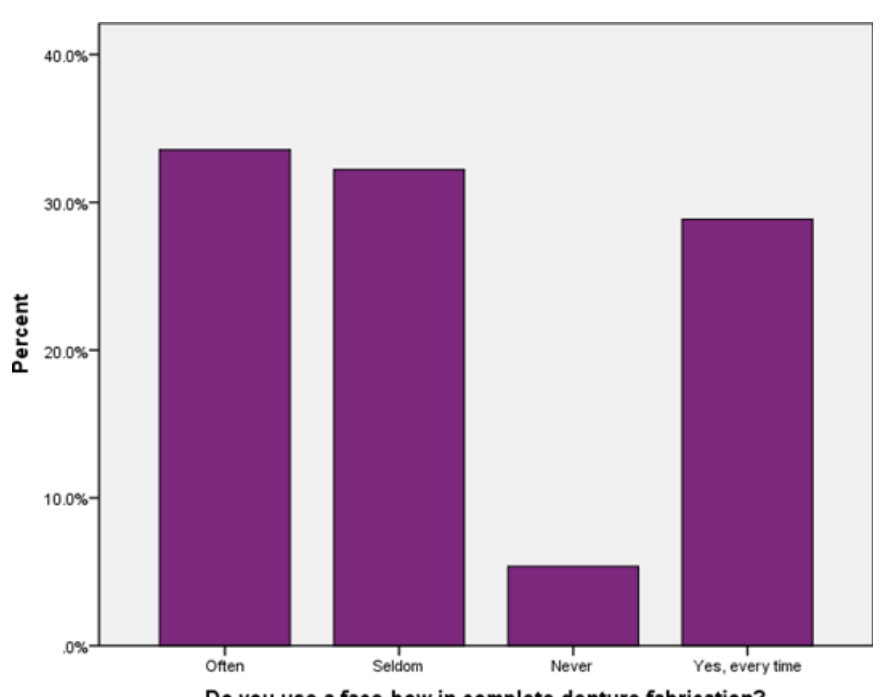

Do you use a face-bow in complete denture fabrication?

Figure 2: Do you use a facebow in complete denture fabrication?

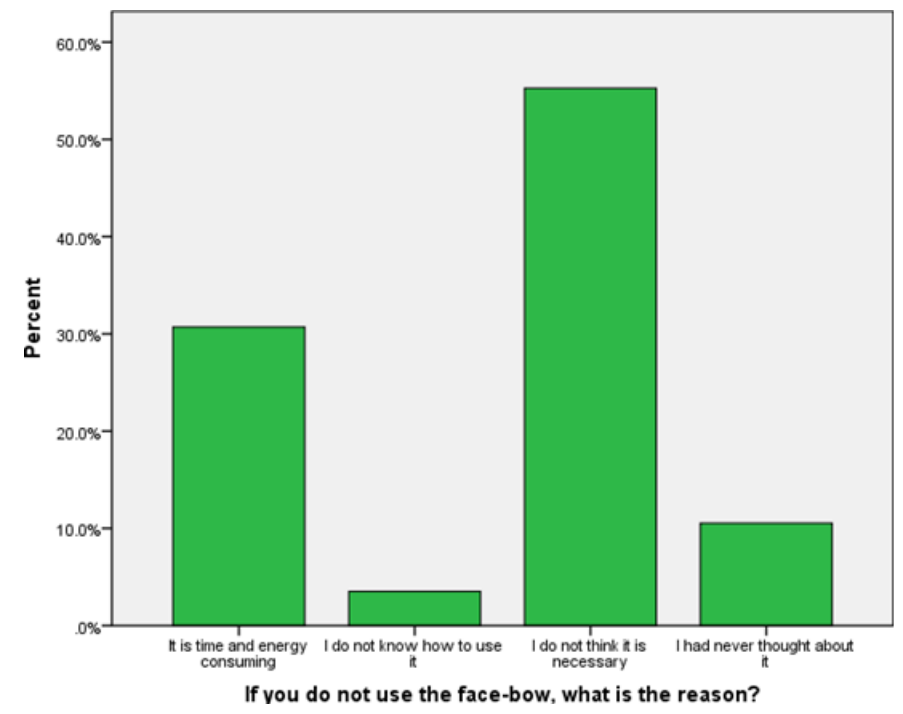

Figure 3: If you do not use the facebow, what is the reason?

\section{Discussion}

It is important to verify that the occlusion and the denture fits in the patient's mouth. However, the need for precise postinsertion adjustment is significantly reduced as the occlusion is strongly designed on the articulator and verified in an attempt at a stage with cast mounted using facebow transfer records. Study to evaluate facebow use among Saudi prosthodontist in the manufacture of complete dentures, among those who had used the facebow in complete denture fabrication, the frequency of use was ' every time' in $28.9 \%$, often in $33.6 \%$ and seldom in $32.2 \%$ of subjects [22-24]. However, $33.6 \%$ of them responded that there is 'no difference' if they used it or not and $37.6 \%$ of them as 'not using it may lower the quality to some extent'. (78.4\%) who had $<=10$ years of experience as a prosthodontist respond yes, they think the quality of the denture made with a simple articulator differs from the adjustable articulator while as $63.6 \%$ who had > 10 years of experience as prosthodontist respond as ' no different' by subjects, which indicates statistically significant association $(\mathrm{p}=0.001)$. however, there is a study for using the facebow among Indian prosthodontist in complete denture fabrication found $33.3 \%$ prosthodontists believed that not using a facebow may lower the quality of the dentures, while $54.17 \%$ prosthodontists believed that there was no difference at all between using and not using a facebow. $43.48 \%$ believed that it was not necessary using facebow in complete denture processing.

$\%$ Believed that it is time and energy consuming procedure. while the same studying China found $97 \%$ of them seldom used a facebow in complete denture fabrication. 39\% of them thought that not using a facebow might lower the quality of complete dentures. There is significant difference in number of post insertion visits for occlusal adjustment between patients who had their dentures made using facebow transfer as compared to patients with dentures made without facebow transfer. The significantly a smaller number of visits showed that there is advantage of using facebow in reducing the number of post insertion visits [4].

39.3 Using the facebow is very critical because if the vertical dimension is changed in the articulator, the use of a facebow shows significant differences regarding the number of laboratory and clinical occlusal contact points compared to a mean setting [13].

\section{Conclusion}

Within the limitation of this study, most of the prosthodontists confirmed that using the facebow is easy to use in fabrication the complete denture and the patients are satisfied with their dentures. Using facebow will reduce the number of visits so it saves time for both the doctor and the patient.

\section{References}

1. Swetha G, Jain AR (2018) KAP on use of facebow in fabrication of complete denture among Indian prosthodontist. Drug Invention Today 10(4): 515-519.

2. Heartwell Charles HM, Rahn AO (1986) Syllabus of complete dentures.

3. Smith PW, McCord JF (2004) What do patients expect from complete dentures? Journal of Dentistry 32(1): 3-7.

4. Mahmood Z, Iqbal Z (2016) Post insertion visits for removable complete dentures made with and without face bow record. Biomedica 32(1): 13.

5. Shodadai SP, Türp JC, Gerds T, Strub JR (2001) Is there a benefit of using an arbitrary facebow for the fabrication of a stabilization appliance? International Journal of Prosthodontics 14(6): 517-522.

6. Nascimento DFF, Patto RBL, Marchini L, Cunha VDPP (2004) Doubleblind study for evaluation of complete dentures made by two techniques with and without face- bow. Brazilian Journal of Oral Sciences 3(9): 439445 .

7. Ellinger CW, Wesley RC, Abadi BJ, Armentrout TM (1989) Patient response to variations in denture technique. Part VII: Twenty-year patient status. The Journal of Prosthetic Dentistry 62(1): 45-48.

8. Duncan JP, Taylor TD (2004) Simplified complete dentures. Dental Clinics of North America 48(3): 625-640. 
9. Kumar M, D'souza DSJ (2010) Comparative evaluation of two techniques in achieving balanced occlusion in complete dentures. Medical Journal Armed Forces India 66(4): 362-366.

10. Hickey JC, Henderson D, Straus R (1969) Patient response to variations in denture technique. Part I. Design of a study. Journal of Prosthetic Dentistry 22(2): 158-170.

11. Carlsson GE (2009) Critical review of some dogmas in prosthodontics. Journal of Prosthodontic Research 53(1): 3-10.

12. Farias Neto A, Dias AHM, de Miranda BFS, de Oliveira AR (2013) Facebow transfer in prosthodontics: a systematic review of the literature. Journal of Oral Rehabilitation 40(9): 686-692.

13. von Stein Lausnitz M, Sterzenbach G, Helm I, Zorn A, Blankenstein FH, et al. (2018) Does a face-bow lead to better occlusion in complete dentures? A randomized controlled trial: part I. Clinical Oral Investigations 22(2): 773-782.

14. Nicol BR, Somes GW, Ellinger CW, Unger JW, Fuhrmann J (1979) Patient response to variations in denture technique. Part II: five-year cephalometric evaluation. The Journal of Prosthetic Dentistry 41(4): 368-372.

15. Palik JF, Nelson DR, White JT (1985) Accuracy of an earpiece face-bow. The Journal of Prosthetic Dentistry 53(6): 800-804.
16. Teteruck WR, Lundeen HC (1966) The accuracy of an ear face-bow. The Journal of Prosthetic Dentistry 16(6): 1039-1046.

17. Heydecke G, Vogeler M, Wolkewitz M, Türp JC, Strub JR (2008) Simplified versus comprehensive fabrication of complete dentures: patient ratings of denture satisfaction from a randomized crossover trial. Quintessence International 39(2).

18. Paulino MR, Alves LR, Gurgel BC, Calderon PS (2015) Simplified versus traditional techniques for complete denture fabrication: a systematic review. The Journal of Prosthetic Dentistry 113(1): 12-16.

19. Khan FR, Ali R, Sheikh A (2018) Utility of facebow in the fabrication of complete dentures, occlusal splints and full arch fixed dental prostheses: A systematic review. Indian Journal of Dental Research 68(12): 1828.

20. Vecchia MPD, Regis RR, Cunha TR, de Andrade IM, da Matta JCS, et al. (2014) A randomized trial on simplified and conventional methods for complete denture fabrication: cost analysis. Journal of Prosthodontics 23(3): 182-191.

21. Wang MQ Xue F, Chen J, Fu K, Cao Y, et al. (2008) Evaluation of the use of and attitudes towards a face-bow in complete denture fabrication: a pilot questionnaire investigation in Chinese prosthodontists. Journal of Oral Rehabilitation 35(9): 677-681.

22. Ye Y, Sun J (2017) Simplified complete denture: a systematic review of the literature. Journal of Prosthodontics 26(4): 267-274. 